\title{
DEVELOPMENT AND REGRESSION OF CIRRHOSIS
}

\author{
Francesca Saffioti and Massimo Pinzani \\ University College London, Institute for Liver and Digestive Health \\ Royal Free Hospital, NW3 2PF London, United Kingdom
}

Short Title: Cirrhosis: fibrosis progression and regression

\section{Address correspondence to:}

Professor Massimo Pinzani, MD, PhD, FRCP

Sheila Sherlock Chair of Hepatology

Director, UCL Institute for Liver and Digestive Health

Royal Free Hospital

Rowland Hill Street

London NW3 2PF

United Kingdom

m.pinzani@ucl.ac.uk

www.ucl.ac.uk/liver-and-digestive-health 


\section{ABSTRACT}

\section{Background}

Liver cirrhosis is the consequence of the wound-healing reaction subsequent to a chronic injury, which leads to a complete derangement of the normal hepatic lobular and vascular architecture. Cirrhosis is characterised by patterns of evolution depending on the causative agent and complex underlining mechanisms in which neo-angiogenesis and necro-inflammation play a key role. The importance of the different cell-type involved and of the extra cellular matrix (ECM) composition and the role of innate immunity, bacterial translocation and oxidative stress are also emerging.

A variable degree of regression of fibrosis and even cirrhosis has been described, in experimental models, after the suspension of the liver disease causative agent. As some individual features influence the rate of fibrosis progression, genetic and epigenetic factors are likely to influence fibrosis regression.

\section{Key Messages}

There is increasing awareness that cirrhosis is not a static condition but a dynamic process. Current semi-quantitative scores and clinical classifications are inaccurate and unable to identify the different evolution phases of the advanced-stage chronic liver diseases (CLD).

The increasing availability of effective aetiology-driven therapeutic options for CLD makes reversion of cirrhosis a more and more possible prospective. However, the removal of the causing agent, depending on the stage of the disease, does not necessarily eliminate the risk of disease progression, decompensation or development of hepatocellular carcinoma. Also, the non-invasive markers currently validated for the assessment of fibrosis are not suitable for an effective evaluation of fibrosis regression.

\section{Conclusions.}

There is a critical need of a system able to more accurately describe the dynamic development of cirrhosis and the impact of tissue fibrosis, neo-angiogenesis, necro-inflammation and attempted regeneration on its evolution.

Effective treatment of CLD can lead to a variable degree of fibrosis regression. New markers able to evaluate this process will need to be detected and validated.

Key Words: Angiogenesis, Chronic Liver Diseases, Cirrhosis, Fibrogenesis, Fibrosis, Portal hypertension. 


\section{INTRODUCTION}

The set of morphologic alterations observed in the end stage of chronic liver diseases (CLD), characterized by a deranged hepatic angio-architecture of the liver parenchyma, are described as "cirrhosis". The wound-healing reaction subsequent to a chronic injury leads to the formation of regenerative parenchymal nodules encapsulated and separated by fibrotic septa altering the normal lobular architecture [1]. Essential alterations of the vascular system in cirrhosis are the formation of intrahepatic shunts, derangement of the vascular network in portal tracts, capillarisation of sinusoids, perisinusoidal fibrosis, vascular thrombosis, under-perfusion of lobular parenchyma and resulting tissue hypoxia [2]. Overall, as just described, cirrhosis could be regarded as a vascular disease of the liver. Consequence of all these changes is the development of portal hypertension (PH) and its life-threatening complications. Furthermore, the constant attempt of hepatocyte regeneration occurring in a fibro-inflammatory tissue microenvironment is responsible of the potential occurrence of hepatocellular carcinoma (HCC).

There is increasing awareness that the concept of liver cirrhosis as a static and irreversible endstage condition has became now inappropriate. Indeed, the advances in the understanding the mechanisms of chronic fibrogenic liver diseases have led to the conclusion that histological semi-quantitative scores, classically used in the attempt to define disease grade (necroinflammatory activity) and stage (tissue fibrosis) on biopsy specimens and the traditional classification of compensated and decompensated disease based on the degree of portal pressure and the occurrence of clinical complications, do not recapitulate and represent the complexity and the spectrum of different stages of advanced-stage CLD and their dynamic development [3].

Furthermore, it is now clear that the different types of CLD have characteristic patterns of fibrotic evolution, with distinctive predominant mechanisms and fibrogenic cell types [4].

In the era in which agents leading to a permanent suppression of hepatitis B virus (HBV) and new antivirals able to eradicate hepatitis $\mathrm{C}$ virus (HCV) in an extremely high percentage of cases have become real therapeutic options, regression of liver fibrosis and even of cirrhosis has become a concrete possibility.

\section{MECHANISMS OF HEPATIC FIBROGENESIS AND THE DEVELOPMENT OF CIRRHOSIS.}

Chronic wound healing and fibrogenesis. The chronic wound-healing process triggered by reiterated liver tissue damage due to infective, metabolic, autoimmune, cholestatic or toxic causes activates a series of pro-fibrogenic mechanisms leading to a variable degree of necrosis/apoptosis of hepatic cells associated with inflammatory infiltration and the progressive accumulation of fibrillar extracellular matrix (ECM) $[5,6]$.

The continuous accumulation of fibrillar ECM is associated with its simultaneous degradation and remodeling, making fibrogenesis a potentially reversible dynamic process. However, with the advancement of CLD fibrosis becomes progressive and to a certain extent irreversible due to the exhaustion of the degradative machinery [5]

The wound-healing process is characterized by a cascade of biological events, which involve cells and soluble factors, aimed at resolving tissue injury (Figure 1). These events and effectors are disposed in a logical sequence with activation of the next step preceded by the resolution of the previous phase [7]. In the presence of a single tissue insult, this mechanism is highly effective, but in the context of a chronic liver injury, deposition of fibrillar matrix rather than 
organized tissue regeneration becomes the best option in order to maintain tissue continuity, leading to progressive scarring of the tissue.

The modification in ECM composition occurring in this process, with a predominance of collagen types I and III, has obvious physiological, biochemical and biomechanical implications. The accumulation of fibrillar ECM in the sinusoidal structures (capillarisation of sinusoids) alters the normal exchange of macromolecules and oxygen between hepatocytes and sinusoidal blood, induces profound changes in the expression of integrins and other cell adhesion molecules, acts as reservoir for pro-inflammatory and pro-fibrogenic mediators, and progressively increases tissue stiffness, a key profibrogenic mechanism leading to the modulation of several cellular function (growth, migration, gene expression) [5-7].

Hepatic stellate cell (HSC) represent the main fibrogenic cell type in the liver. Presenting ultrastructural features of vascular pericytes, they have also a potential role in the regulation of sinusoidal blood flow. The process of HSC activation and phenotypical transformation into myofibroblasts, as well as their pro-fibrogenic role, have been extensively clarified. It is now evident that distinct ECM-producing cells, each with a distinct localization and a characteristic immunohistochemical and/or electron microscopic phenotype, are likely to contribute to liver fibrosis $[5,6]$. These include: fibroblasts and myofibroblasts of the portal tract, smooth muscle cells localized in vessel walls and myofibroblasts localized around the centrolobular vein. Myofibroblasts may also derive from a population of circulating fibroblast-like cells derived from bone marrow stem cells, called "fibrocytes". The relative participation of these different ECMproducing cells depends on the pattern of fibrosis evolution [8]

Although cell biology of liver fibrosis has been mostly framed around activated HSC and more in general myofibroblast-like cells, other cells play a fundamental role in the fibrogenic process. In particular, macrophages are indispensable for both fibrosis progression and regression [9] and their activity is modulated by the direction of the cytokines and other soluble factors network towards progression or resolution. Platelet aggregation/degranulation, the activation of complement and of the coagulation cascade represent initial events of the wound-healing reaction. Accordingly, anticoagulants or antiplatelet agents have been shown to prevent fibrosis by acting on HSCs, in several animal models [10]. Cholangiocytes play a major role and contribute to the peribiliary fibrogenic process in CLD characterised by damage, proliferation and activation of the biliary epithelium. These cells express a wide range of profibrogenic molecules and, when activated, stimulate fibrogenic, apoptotic and proliferative response through an intense cross-talk with portal fibroblasts/myofibroblasts and HSC mediated by proinflammatory and chemotactic cytokines such as IL-6, TNF- $\alpha$, IL-8, and MCP-1 [11].

There is increasing evidence that the alterations of mechanisms of innate immunity occurring in systemic pro-inflammatory and pro-fibrogenic status and bacterial translocation affect CLD progression. In particular, a combination of dysbiosis and increased intestinal permeability, altered gut defences and reduced immunological surveillance leads to increased migration of bacteria or bacterial products from the intestinal lumen to mesenteric lymph-nodes or other extraintestinal sites [12]. Recently, the attention is focused on bacterial products named pathogen-associated molecular patterns (PAMPs): lipoproteins, bacterial DNA and doublestranded RNA recognized by pattern recognition receptors (PRRs) present on a wide variety of cells [13]. The interaction between PAMPs and PRRs serves as a first-line defence during infection and activates numerous pro-inflammatory cytokine and chemokine responses. Fibroblasts, myofibroblasts and vascular pericytes express a variety of PRRs (including toll-like receptors -TLRs) which, when bound by their ligands, can promote the activation/differentiation of these cells into collagen-producing myofibroblasts and the establishment of a proinflammatory/pro-fibrogenic condition in the portal circulation $[14,15]$. 
Neo-angiogenesis. In the last decades, increasing attention has been given to the key interplay between neo-angiogenesis and fibrogenesis and its role in the progression of CLD towards cirrhosis.

Angiogenesis and up-regulation of vascular endothelium growth factor (VEGF) have been documented in experimental models of acute and chronic liver injury [16] as well as in specimens from human fibrotic/cirrhotic liver and hepatocellular carcinoma $[\mathbf{1 7}, \mathbf{1 8}]$.

When activated by hypoxia occurring in the context of a chronic wound healing reaction, HCS represent a significant source of angiogenic cytokines and tend to acquire a generic "proangiogenic" phenotype. They represent the target of the multiple actions of VEGF and angiopoietin 1 (Ang-1), including stimulation of proliferation, collagen type I synthesis and recruitment of other HSC [19].

The intrahepatic vascular remodelling occurring in CLD (capillarisation of sinusoids, development of intrahepatic shunts) leads to increased hepatic resistance, $\mathrm{PH}$ and decreased effective hepatocyte perfusion. The process of revascularisation is characterised by a chaotic pattern: many of the neoformed vessels have a "blind end" and only a minority of attempts result in portal-central anastomoses. These vascular structures follow irregular patterns and are surrounded by fibrotic tissue containing contractile cells (activated HSC, myofibroblasts). This leads to increased hepatic resistance and further reduction of the effective perfusion of hepatocytes, thus reiterating the hypoxic stimulus to angiogenesis and fibrogenesis [20].

\section{Fibrosis and portal hypertension}

Portal hypertension $(\mathrm{PH})$ is firstly the result of an increased intrahepatic resistance caused by architectural distortion (fibrous tissue, regenerative nodules), endothelial dysfunction leading to intrahepatic vasoconstriction and intrahepatic vascular shunts between afferent and efferent vessels of the liver [21,22]. Subsequently, portal hypertension is aggravated by an increase of portal and hepatic arterial blood flow.

Hepatic venous pressure gradient (HVPG), an indirect measure of portal pressure, is the best predictor of the development of PH $[23,24]$. Progressive increases in HVPG correlate with increasing severity of liver disease: normal, chronic hepatitis, pre-cirrhosis and cirrhosis [25]. Despite the fact that histological features of disease progression within the stage of cirrhosis (since this is identified by the highest value of the currently used scoring systems) have not been traditionally linked to clinical outcomes, the analysis of some histologic features in cirrhotic liver biopsies may have important prognostic implications. For example, the thickness of fibrous septa correlates with HVPG and is an independent predictor of both clinically significant portal hypertension [26] and clinical decompensation [27].

The recently introduced possibility to measure the quantity and the distribution of collagen as collagen proportional area (CPA), a new histological marker obtained by digital video imaging analysis, has allowed to better define the relationship between evolution of fibrosis and worsening of $\mathrm{PH}$. Furthermore, scoring cirrhosis with a continuous scale may allow to predict relevant clinical outcomes [28,29].

\section{AETIOLOGY-DRIVEN FIBROGENETIC MECHANISMS AND PATTERNS}

In recent years, the increasing awareness that different CLD have distinct patterns of fibrotic development has led to the concept of "aetiology-driven cirrhosis" [30,31].

The different patterns of fibrogenic evolution are related to various factors, such as the topographic localization of tissue damage, the dynamics of the necro-inflammatory infiltrate, 
the distribution of fibrosis, the relative concentration of pro-fibrogenic factors, the main profibrogenic mechanism(s) as well as the prevalent cellular effectors. Time to disease progression, distribution of fibrosis and onset/progression of $\mathrm{PH}$ are correlated and depend on the aetiological agent.

The fibrotic pattern of chronic viral hepatitis is characterised by portal-central septa (likely the results of portal-central bridging necrosis), the presence of "interface" hepatitis and the development of portal-portal septa and septa ending blind in the parenchyma and a rapid derangement of the vascular connections with the portal system, which causes early portal hypertension. In biliary diseases, instead, the central vein and its connections with the portal tract are preserved until late stages and fibrosis. This is due to the co-proliferation of reactive bile ductules and periductular myofibroblast-like cells at the portal-parenchymal interface, which tends to follow a portal-to-portal direction, leading to the formation of portal-portal septa surrounding liver nodules and to the development of pre-sinusoidal resistance to portal flow. In alcoholic and metabolic liver diseases the deposition of fibrillar matrix is concentrated around the sinusoids (capillarisation) and around groups of hepatocytes (chicken-wire pattern). Finally, fibrosis secondary to venous outflow problems (e.g. chronic heart failure) is characterised by development of central-to-central septa and "reversed lobulation" (Table 1).

Recent studies quantifying the amount of fibrosis present in cirrhotic livers of different aetiologies on explants by means of CPA provide a proof of concept of the above considerations $[28,32]$.

\section{REVERSIBILITY OF FIBROSIS AND CIRRHOSIS}

Evidence of fibrosis and even cirrhosis regression has been reported in CLD of different aetiologies, including viral hepatitis [33,34], autoimmune hepatitis [35], alcoholic and nonalcoholic steatohepatitis [36,37], although, in most cases, the experienced liver pathologists who analysed these results have been in agreement only for a variable degree of fibrosis regression, but not for cirrhosis reversion [38,39]. Furthermore, it has to be underlined that the background scientific information is based on data obtained in experimental animal models, in which liver cirrhosis can be induced in only a few weeks and quickly reverted after the suspension of the exposure to the causative agent. This possibility is far from being substantiated in humans. Available evidence suggest that even extensive fibrosis regression is characterised by the persistence of veno-portal adhesions and "arterialized" sinusoids in the context of intrahepatic artero-venous shunts [40], raising serious doubts about a potential regression of the intrahepatic vasculature abnormalities in human cirrhotic liver.

Critical events for the reversibility of fibrosis are the more or less rapid switch-off of the chronic wound-healing process characterized by the progressive reduction of necro-inflammation and the following reduction of the number of activated HSC trough pathways of apoptosis, senescence and reversion to quiescence. In addition, it has been demonstrated that macrophages play a key-role in the resolution of fibrosis, and data have raised the possibility that different classes of macrophages respectively responsible for fibrosis progression or regression, might exist [41].

Cirrhosis has a very broad spectrum of variants (early, fully developed, "active" and "inactive") and there is clear lack of an accurate scoring system able to identify the different evolution phases of the advanced-stage CLD and to better describe the dynamic development of the disease, its pathophysiology or the impact of tissue fibrosis, neo-angiogenesis, necroinflammation and attempted regeneration on the often life-threatening clinical manifestations. At the base of the problem is the fact that the staging of fibrosis is obtained using semi- 
quantitative scoring systems, in which cirrhosis is always represented by the highest score and considered as an end-stage of CLD [42]. On the other hand, the term "cirrhosis" identifies an advanced phase of CLD that per se is neither morphologically or clinically an end stage, particularly with the prospective of novel treatments able to stabilize or even reduce tissue fibrosis. The currently used classification of cirrhotic patients in 5 stages on the basis of the major clinical manifestations of their disease (stage 1: compensated with no esophageal varices; stage 2: compensated with esophageal varices, stage 3: ascites, stage 4: gastrointestinal bleeding, stage 5: infections and renal failure) is also inadequate in predicting evolution of disease and life-threatening events [2,3].

It is expected that ability to revert and the relevance of different mechanisms involved in the regression of fibrosis may differ according to the effective stage of the disease (pre-cirrhosis, early cirrhosis, advanced/established cirrhosis). In fact, several studies have demonstrated the capacity of the healing liver to reabsorb scar tissue following an effective causative treatment (i.e. sustained viral response, abstinence from alcohol etc.), while the possibility of established cirrhosis to reverse to normal is still quite doubtful [41]. Along these lines, it is clear that scar tissue in the liver of patients with a long-standing CLD is characterized by different stages of biochemical and biological evolution compared to that of a disease with recent onset. Within the same liver, in fact, there are different types of scar tissue with different potential and dynamics of reversibility once the etiological agent is eradicated and/or anti-fibrogenic strategy is established.

Fibrotic deposition related to recent disease and characterized by the presence of thin reticulin fibres, often in the presence of a diffuse inflammatory infiltrate, is likely fully reversible, whereas long standing fibrosis, characterised by extensive collagen cross-linking by tissue transglutaminase, presence of elastin, dense acellular/paucicellular ECM and decreased expression and/or activity of specific metalloproteinases, is not [43]. Even more, it has been shown that long-term fibrogenesis occurring in human CLD is characterized by a progressive resistance to apoptosis of hepatic stellate cells/myofibroblasts with the consequent immovability of a critical mass of pro-fibrogenic cells [44].

Portal hypertension reflects the histological changes typical of advanced stage liver disease (acellular fibrosis, extensive collagen crosslinking, elastin deposition) as well as the disease severity. When hepatic venous pressure gradient (HVPG) overcomes $12 \mathrm{mmHg}$, cirrhosis becomes a systemic disease, which severity and evolution are largely independent of liver tissue fibrosis. The absence of PH seems, then, to be a crucial determinant for the possibility of fibrosis regression in advanced-sage CLD [41].

The new interferon-free regimens for the treatment of HCV allow a sustained viral response (SVR) in almost $100 \%$ of the treated patients including patients with cirrhosis. Hence, viral eradication can be achieved also in advanced stages of the disease. SVR is likely to be followed by a decline of necro-inflammation and fibrosis progression, as well as by an improvement of PH and its clinical manifestations, risk of hepatocellular carcinoma (HCC), liver-related mortality and liver transplantation $[\mathbf{4 5 , 4 6 ] \text { . }}$

Similarly, NUC agents suppressing HBV DNA levels prevent disease progression and improve patients' survival. Long-term treatment of HBV with NUC can result in histological reduction or stabilisation of liver fibrosis in most patients $[47,48]$.

However, obtaining a SVR in patients with HCV-related cirrhosis does not necessarily prevent the immediate risk of decompensation and/or of HCC. In fact, it has been reported that SVR significantly reduces the risk of decompensation and liver related death related only in patients categorised as "stage 1", who do not present clinically significant PH. Furthermore, HCV clearance in compensated patients with a significant grade of $\mathrm{PH}$ does not lead to the abolition 
of the risk of progression towards decompensation or to a significant reduction of PH [46]. In this context it is important to keep in mind that, despite the evidence of fibrosis (and even cirrhosis) regression in patients undergoing SVR, other processes such as ductular proliferation, loss of lobular zonation, portal inflammation and sinusoidal capillarisation may not regress following SVR [49].

It is likely that, beyond a certain level, the fibrogenic process may acquire a relative autonomy, leading to a further progression of the disease independently of the discontinuation of the causative agent and the consequent reduction of hepatocellular necrosis and inflammation. This may depend on the significant hyperplasia of activated HSC and myofibroblasts and the activation of antiapoptotic pathways in these cells [50], to the derangement of the hepatic angioarchitecture consequent to neoangiogenesis and the elevated tissue tension due to fibrotic tissue contraction, which are only minimally affected by the reduction of necroinflammation. In addition, the persistence of profibrogenic cofactors such as excessive alcohol intake and baseline metabolic factors is likely to negatively influence the extent and rapidity of fibrosis regression despite an effective etiological treatment.

Since there is clear sufficient evidence that some individual factors influence the rate of fibrosis progression leading to the differentiation of patients in slow, intermediate and fast "fibrosers", it is conceivable that the presence of genetic/epigenetics determinants affecting the rapidity of fibrosis progression may also influence fibrosis regression [41].

\section{CONCLUSIONS}

Thanks to the advancement in understanding the mechanisms leading to advanced stage CLD, it appears more and more clear that the disease is sustained by different prevalent mechanisms depending on the triggering aetiology, and that the word "cirrhosis", traditionally implying a static and irreversible condition, is not reflecting the actual dynamicity of the underlining processes.

Accordingly, there is an urgent need to redefine cirrhosis in order to better reflect its progression, reversibility, and prognosis, as well as its relationship to $\mathrm{PH}$ and fibrogenesis.

This potentially calls for different morphological classifications, different non-invasive diagnostic and prognostic indicators, different aetiology-driven and/or antifibrotic therapies and, most importantly, different expectations on the effective reversibility of fibrosis and cirrhosis. 


\section{References}

1. Rappaport AM, McPhee PJ, Fisher MM, Phillips MJ. The scarring of the liver acini (cirrhosis). Tridimensional and microcirculatory considerations. Virchows Arch [A] 1983; 402:107-137.

2. Wanless IR, Wong F., Blendis LM, Greig P, Heathcote EJ, Levy G. Hepatic and portal vein thrombosis in cirrhosis: possible role in development of parenchymal extinction and portal hypertension. Hepatology 1995; 21:1238-1247.

3. Garcia-Tsao G, Friedman S, Iredale J, Pinzani M. Now there are many (stages) where before there was one: In search of a pathophysiological classification of cirrhosis. Hepatology 2010;51:1445-1449.

4. Hytiroglou P, Snover DC, Alves V, Balabaud C, Bhathal PS, Bioulac-Sage P, et al. Beyond "cirrhosis": a proposal from the International Liver Pathology Study Group. Am J Clin Pathol 2012; 137:5-9.

5. Friedman SL. Mechanisms of hepatic fibrogenesis. Gastroenterology 2008; 134:16551669.

6. Pinzani M, Macias-Barragan J. Update on the pathophysiology of liver fibrosis. Expert Rev Gastroenterol Hepatol 2010; 4:459-72.

7. Wynn TA. Common and unique mechanisms regulate fibrosis in various fibroproliferative diseases. J Clin Invest. 117:524-529 (2007).

8. Quan TE, Cowper SE, Bucala R. The role of circulating fibrocytes in fibrosis. Curr Rheumatol Rep 2006; 8:145-150.

9. Fallowfield JA, Mizuno M, Kendall TJ et al. Scar-associated macrophages are a major source of hepatic matrix metalloproteinase-13 and facilitate the resolution of murine hepatic fibrosis. J Immunol 2007; 178:5288-5295.

10. Calvaruso V, Maimone S, Gatt A, Tuddenham E, Thursz M, Pinzani M, Burroughs AK. Coagulation and fibrosis in chronic liver disease. Gut. 2008; 57:1722-7.

11. O'Hara SP, Tabibian JH, Splinter PL, LaRusso NF. The dynamic biliary epithelia: molecules, pathways, and disease. J Hepatol 2013; 58:575-82.

12. Schnabl B, Brenner DA Interactions between the intestinal microbiome and liver diseases. Gastroenterology 2014; 146:1513-24.

13. Akira S, Takeda K. Toll-like receptor signalling. Nat Rev Immunol 2004; 4:499-511.

14. Otte JM, Rosenberg IM, Podolsky DK. Intestinal myofibroblasts in innate immune responses of the intestine. Gastroenterology 2003; 124:1866-1878.

15. Coelho AL, Hogaboam CM, Kunkel SL. Chemokines provide the sustained inflammatory bridge between innate and acquired immunity. Cytokine Growth Factor Rev 2005; 16:553-560.

16. Corpechot C, Barbu V, Wendum D et al. Hypoxia-induced VEGF and collagen I expressions are associated with angiogenesis and fibrogenesis in experimental cirrhosis. Hepatology 2002; 35:1010-1021.

17. Shimoda K, Mori M, Shibuta K, Banner B, Barnard G. Vascular endothelial growth factor / vascular permeability factor mRNA expression in patients with chronic hepatitis $C$ and hepatocellular carcinoma. Int J Oncol 1999; 14:353-359.

18. Medina J, Sanz-Cameno P, Garcia-Buey L, Martin-Vilchez S, Lopez-Cabrera M, MorenoOtero R. Evidence of angiogenesis in primary biliary cirrhosis: an immunohistochemical descriptive study. J Hepatol 2005; 42:124-131.

19. Novo E, Cannito $S$, Zamara $E$ et al. Vascular endothelial growth factor and angiopoietin-1 as hypoxia-dependent autocrine and paracrine factors stimulating migration and chemotaxis of activated human hepatic stellate cells. Am J Pathol 2007; 170:1942-53. 
20. Fernández M, Semela D, Bruix J, Colle I, Pinzani M, Bosch J. Angiogenesis in liver disease. J Hepatol. 2009; 50:604-20.

21. D'Amico G, Garcia-Tsao G, Pagliaro L. Natural history and prognostic indicators of survival in cirrhosis. A systematic review of 118 studies. J Hepatol 2006; 44:217-231.

22. Iwakiri Y, Groszmann RJ. Vascular endothelial dysfunction in cirrhosis. J Hepatol 2007; 46:927-934.

23. Ripoll C, Groszmann R, Garcia-Tsao G, Grace N, Burroughs A, Planas R et al. Hepatic venous pressure gradient predicts clinical decompensation in patients with compensated cirrhosis. Gastroenterology 2007; 133:481-488.

24. Casado M, Bosch J, Garcia-Pagan JC, Bru C, Banares R, Bandi JC et al. Clinical events after transjugular intrahepatic portosystemic shunt: correlation with hemodynamic findings. Gastroenterology 1998; 114:1296-1303.

25. Van Leeuwen DJ, Howe SC, Scheuer PJ, Sherlock S. Portal hypertension in chronic hepatitis: relationship to morphological changes. Gut 1990; 31:339-343.

26. Nagula S, Jain D, Groszmann RJ, Garcia-Tsao G. Histological-hemodynamic correlation in cirrhosis-a histological classification of the severity of cirrhosis. J Hepatol 2006; 44:111117.

27. Sreenivasan P, Inayat I, Jain D, Bari K, Garcia-Tsao G. Histological-clinical correlation in cirrhosis - Validation of a histological classification of the severity of cirrhosis. Hepatology 2007; 46 (Suppl 1): 579A (Abstract).

28. Calvaruso V, Burroughs AK, Standish R, Manousou P, Grillo F, Leandro G, Maimone S, Pleguezuelo M, Xirouchakis I, Guerrini GP, Patch D, Yu D, O'Beirne J, Dhillon AP. Computer-assisted image analysis of liver collagen: relationship to Ishak scoring and hepatic venous pressure gradient. Hepatology 2009; 49:1236-1244.

29. Germani G, Dhillon A, Andreana L, Calvaruso V, Manousou P, Isgró G, Burroughs AK. Histological subclassification of cirrhosis. Hepatology 2010; 52:804-805.

30. Tsochatzis EA, Bosch J, Burroughs AK. New therapeutic paradigm for patients with cirrhosis. Hepatology 2012; 56:1983-92.

31. Pinzani M, Rombouts K. Liver fibrosis: from the bench to clinical targets. Dig Liver Dis 2004; 36:231-42.

32. Hall A, Germani G, Isgrò $G$, et al. Fibrosis distribution in explanted cirrhotic livers. Histopathology 2012; 60:270-7.

33. Brown A, Goodman Z. Hepatitis B-associated fibrosis and fibrosis/cirrhosis regression with nucleoside and nucleotide analogs. Expert Rev Gastroenterol Hepatol. 2012 Apr;6(2):187-98.

34. Serpaggi J, Carnot F, Nalpas B, Canioni D, Guéchot J, Lebray P, Vallet-Pichard A, Fontaine $H$, Bedossa $P$, Pol S. Direct and indirect evidence for the reversibility of cirrhosis. Hum Pathol 2006; 37:1519-1526.

35. Dufour JF, DeLellis R, Kaplan MM. Reversibility of hepatic fibrosis in autoimmune hepatitis. Ann Intern Med 1997; 127:981-985.

36. Wakim-Fleming J, Mullen KD. Long-term management of alcoholic liver disease. Clin Liver Dis 2005; 9:135-149.

37. Dixon JB, Bhathal PS, Hughes NR, O'Brien PE. Nonalcoholic fatty liver disease: improvement in liver histological analysis with weight loss. Hepatology 2004; 39:16471654.

38. Desmet VJ, Roskams T. Reversal of cirrhosis: evidence based medicine? Gastroenterology 2003; 125:629-630.

39. Desmet VJ, Roskams T. Cirrhosis reversal: a duel between dogma and myth. J Hepatol 2004; 40:860-867. 
40. Wanless IR, Nakashima E, Sherman M. Regression of human cirrhosis: morphologic features and the genesis of incomplete septal cirrhosis. Arch Pathol Lab Med 2000; 124:1599-1607.

41. Massimo Pinzani. Liver Fibrosis in the Post-HCV Era. Semin Liver Dis. 2015;35(2):157-65.

42. Desmet VJ. Milestones in liver disease. Scoring chronic hepatitis. J Hepatol 2003; 38:382-386.

43. Issa R, Zhou X, Constandinou CM, Fallowfield J, Millward-Sadler H, Gaca MD, Sands E, Suliman I, Trim N, Knorr A, Arthur MJ, Benyon RC, Iredale JP. Spontaneous recovery from micronodular cirrhosis: evidence for incomplete resolution associated with matrix cross-linking. Gastroenterology 2004; 126:1795-1808.

44. Novo E, Marra F, Zamara E, Valfrè di Bonzo L, Monitillo L, Cannito S, Petrai I, Mazzocca A, Bonacchi A, De Franco RS, Colombatto S, Autelli R, Pinzani M, Parola M. Overexpression of $\mathrm{Bcl}-2$ by activated human hepatic stellate cells: resistance to apoptosis as a mechanism of progressive hepatic fibrogenesis in humans. Gut 2006; 55:1174-1182.

45. Morgan RL, Baack B, Smith BD, Yartel A, Pitasi M, Falck-Ytter Y. Eradication of hepatitis C virus infection and the development of hepatocellular carcinoma: a meta-analysis of observational studies. Ann Intern Med 2013;158(5 Pt 1):329-337.

46. Veldt BJ, Heathcote EJ, Wedemeyer $\mathrm{H}$, et al. Sustained virologic response and clinical outcomes in patients with chronic hepatitis $\mathrm{C}$ and advanced fibrosis. Ann Intern Med 2007;147(10):677-684.

47. Brown A, Goodman Z. Hepatitis B-associated fibrosis and fibrosis/ cirrhosis regression with nucleoside and nucleotide analogs. Expert Rev Gastroenterol Hepatol 2012;6(2):187-198.

48. Calvaruso V, Craxì A. Regression of fibrosis after HBV antiviral therapy. Is cirrhosis reversible? Liver Int 2014;34(Suppl 1):85-90.

49. D'Ambrosio R, Aghemo A, Rumi MG, et al. A morphometric and immunohistochemical study to assess the benefit of a sustained virological response in hepatitis $C$ virus patients with cirrhosis. Hepatology 2012;56(2):532-543.

50. Novo E, Marra F, Zamara E, et al. Overexpression of Bcl-2 by activated human hepatic stellate cells: resistance to apoptosis as a mechanism of progressive hepatic fibrogenesis in humans. Gut 2006;55(8):1174-1182. 


\begin{tabular}{|c|c|c|c|c|c|}
\hline Etiology & $\begin{array}{c}\text { Prevalent } \\
\text { mechanism }\end{array}$ & $\begin{array}{c}\text { Fibrosis } \\
\text { distribution }\end{array}$ & Main characteristic & $\begin{array}{c}\text { Main cellular } \\
\text { effector }\end{array}$ & PH \\
\hline $\begin{array}{ll}\text { - } & \text { Viral } \\
\text { - } & \text { Autoimmune }\end{array}$ & $\begin{array}{l}\text { - Chronic wound } \\
\text { healing }\end{array}$ & Portal-to-central & $\begin{array}{l}\text { - “Interface” hepatitis } \\
\text { - Portal-portal septa } \\
\text { - Septa ending blind in } \\
\text { the parenchyma } \\
\text { - Rapid derangement of } \\
\text { the vascular } \\
\text { connections with the } \\
\text { portal system }\end{array}$ & - HSC & Early \\
\hline $\begin{array}{ll}\text { - } & \text { Primary } \\
\text { biliary } \\
\text { cirrhosis } \\
\text { - Primary } \\
\text { sclerosing } \\
\text { cholangitis } \\
\text { Secondary } \\
\text { biliary } \\
\text { cirrhosis }\end{array}$ & $\begin{array}{l}\text { - Epithelial } \\
\text { mesenchimal } \\
\text { disruption } \\
\text { - Reactive } \\
\text { cholangiocytes } \\
\text { - Bile salt toxicity }\end{array}$ & Portal-to-portal & $\begin{array}{l}\text { - Proliferation of } \\
\text { reactive bile ductules } \\
\text { and periductular } \\
\text { myofibroblast-like } \\
\text { cells at the portal- } \\
\text { parenchymal } \\
\text { interface } \\
\text { - Portal-portal septa } \\
\text { - Development of pre- } \\
\text { sinusoidal resistance } \\
\text { to portal flow }\end{array}$ & $\begin{array}{l}\text { - Cholangiocytes } \\
\text { - Fibroblasts } \\
\text { - Myofibroblasts }\end{array}$ & Late \\
\hline $\begin{array}{l}\text { - Alcoholic } \\
\text { Metabolic } \\
\text { (- NASH } \\
\text { - Wilson } \\
\text { disease } \\
\text { - Haemo } \\
\text { cromatosis) }\end{array}$ & $\begin{array}{l}\text { - Oxydative } \\
\text { stress } \\
\text { - Reactive } \\
\text { aldehydes } \\
\text { - Lipotoxicity }\end{array}$ & $\begin{array}{l}\text { Perisinusoidal } \\
\text { Pericellular }\end{array}$ & $\begin{array}{l}\text { - Capillarisation } \\
\text { - “Chicken-wire } \\
\text { pattern” }\end{array}$ & - HSC & Late \\
\hline $\begin{array}{l}\text { - } \quad \begin{array}{l}\text { Budd-Chiari } \\
\text { Syndrome }\end{array} \\
\text { - } \quad \begin{array}{l}\text { Chronic heart } \\
\text { failure }\end{array}\end{array}$ & $\begin{array}{l}\text { - Venous outflow } \\
\text { problems }\end{array}$ & $\begin{array}{l}\text { Central-to- } \\
\text { central }\end{array}$ & - “Reversed lobulation” & - HSC & Early \\
\hline
\end{tabular}

PH: portal hypertension. HSC: hepatic stellate cells. NASH: non-alcoholic steatohepatitis. 